OPEN ACCESS

Edited by:

Fatima Baltazar

University of Minho, Portugal

Reviewed by:

Andreas Papapetropoulos,

National and Kapodistrian University

of Athens, Greece

Cesare Indiveri,

University of Calabria, Italy

*Correspondence:

Jacinta Serpa

jacinta.serpa@nms.unl.pt

Specialty section:

This article was submitted to

Cancer Metabolism

a section of the journal

Frontiers in Oncology

Received: 07 February 2020

Accepted: 14 May 2020

Published: 23 June 2020

Citation:

Serpa J (2020) Cysteine as a Carbon

Source, a Hot Spot in Cancer Cells Survival. Front. Oncol. 10:947. doi: 10.3389/fonc.2020.00947

\section{Cysteine as a Carbon Source, a Hot Spot in Cancer Cells Survival}

\author{
Jacinta Serpa ${ }^{1,2 *}$ \\ ${ }^{1}$ CEDOC, Chronic Diseases Research Centre, NOVA Medical School - Faculdade de Ciências Médicas, Universidade NOVA \\ de Lisboa, Lisbon, Portugal, ${ }^{2}$ Instituto Português de Oncologia de Lisboa Francisco Gentil (IPOLFG), Lisbon, Portugal
}

Cancer cells undergo a metabolic rewiring in order to fulfill the energy and biomass requirements. Cysteine is a pivotal organic compound that contributes for cancer metabolic remodeling at three different levels: (1) in redox control, free or as a component of glutathione; (2) in ATP production, via hydrogen sulfide $\left(\mathrm{H}_{2} \mathrm{~S}\right)$ production, serving as a donor to electron transport chain (ETC), and (3) as a carbon source for biomass and energy production. In the present review, emphasis will be given to the role of cysteine as a carbon source, focusing on the metabolic reliance on cysteine, benefiting the metabolic fitness and survival of cancer cells. Therefore, the interplay between cysteine metabolism and other metabolic pathways, as well as the regulation of cysteine metabolism related enzymes and transporters, will be also addressed. Finally, the usefulness of cysteine metabolic route as a target in cancer treatment will be highlighted.

Keywords: cysteine, cysteine metabolism, cysteine transport, cancer metabolic remodeling, targeting cysteine route

\section{INTRODUCTION}

Posited as a glutathione precursor or as a source of sulfur and carbon, cysteine contributes for cancer cell strongness and prosperity, allowing their survival upon stressful microenvironmental conditions and upon drugs exposure $(1,2)$.

In the recent years, the role of cysteine and glutathione in the scavenging of reactive oxygen species (ROS), contributing for chemoresistance (3-9) have been under scrutiny. Cysteine and glutathione are crucial in the maintenance of the metabolic course (10-13), since the cancer metabolic rewiring implies the generation of oxidative stress (14-16). Nevertheless, cysteine has been underestimated as a carbon source, due to the core position of glycolysis in the cellular biosynthesis and bioenergetics, being major emphasis given to glucose as a preferential fuel and to glutamine as its main substitute [as reviewed in $(17,18)$ ].

Despite few recent studies addressing cysteine as a key organic compound in cancer, the actual meaning of cancer cells' cysteine dependency is far from being completely known. Therefore, in the next sections, the metabolic dynamics of cysteine in cancer and the interconnections between cysteine metabolism and other metabolic pathways will be addressed.

\section{CYSTEINE AS A CARBON SOURCE IN CANCER}

The usefulness of cysteine as a carbon source is visible along the cysteine catabolic pathway, since cysteine catabolism originates organic compounds used in carbon and energy metabolism (19-23). 


\section{Cysteine Metabolism and Other Metabolic Pathways Intercrosses}

The metabolic reliance of cancer cells on cysteine promotes a better adaptation to metabolically damaging conditions and the development of chemoresistance $(1,2)$, accounting for cancer success.

Cysteine catabolism occurs upon the action of four enzymes: cystathionine $\beta$-synthase (CBS); cystathionine $\gamma$-lyase (CSE), and 3-mercapto-pyruvate sulfurtransferase (MST), which works together with cysteine aminotransferase (CAT) $(24,25)$. Cysteine-derived organic compounds, such as pyruvate, $\alpha$-ketobutyrate and glutamate (26), supply other metabolic pathways (Figure 1A), such as the tricarboxylic acid (TCA) cycle and glucose-related pathways. Besides organic compounds, cysteine catabolism generates hydrogen sulfide $\left(\mathrm{H}_{2} \mathrm{~S}\right)$ (27-32). Thus, the role of the enzymes has been directly associated with ATP production, as $\mathrm{H}_{2} \mathrm{~S}$ can donate electrons to electron transport chain (ETC) $(27,28,33,34)$, and indirectly with the role of $\mathrm{H}_{2} \mathrm{~S}$ as a paracrine and an autocrine signaling molecule in cancer, regulating cell proliferation, bioenergetics and angiogenesis $(35,36)$. The link between the enzymes involved in cysteine degradation and malignancy $(27-29,37-42)$ is thereby not easy to distinguish as being specifically related to the release of $\mathrm{H}_{2} \mathrm{~S}$ or to the generation of organic compounds.

Cysteine catabolism cannot be addressed without mentioning that de novo cysteine synthesis occurs through the transsulfuration pathway (TSP), deriving from methionine and serine (Figure 1B), which makes the synthesis of cysteine dependent on the availability of methionine cycle intermediates (43). Serine and glycine can be glutamine-originated, making an interconnection of glutamine and cysteine metabolism (3). In methionine cycle, homocysteine is synthesized, being further condensed with serine to generate cystathionine, by CBS. Afterwards cystathionine is hydrolyzed by CSE, giving rise to cysteine, and other compounds (e.g., ammonia, $\alpha$-ketobutyrate or propionate) [as reviewed (44)].

Pyruvate kinase $(\mathrm{PK})$ is considered a main regulator of energy homeostasis by the generation of glucose-derived pyruvate (45), but recently, cysteine catabolism and serine synthesis pathway (SSP) were considered the main supplier of pyruvate in cancer cells, as a way of overcoming the lack of PK expression (46).

\section{One-Carbon Metabolism Concurrently Depends on and Controls Cysteine Bioavailability}

The one-carbon metabolism is constituted by the methionine cycle and the folate cycle, which are dependent on serine and glycine bioavailability and from which certain intermediates are deviated to form cysteine (Figure 1B). Serine is synthesized from glucose and glutamine, and in turn serine gives rise to glycine [as reviewed (47)], which enters the folate cycle (48). Interestingly, cancer cells produce glycine from serine rather than import glycine (49), pointing out the upregulation of SSP as a cancer specialization. Moreover, phosphoglycerate dehydrogenase, a SSP key enzyme, was recently proposed as a poor prognosis marker in lung (50), gastric (51), and pancreatic (52) carcinomas.

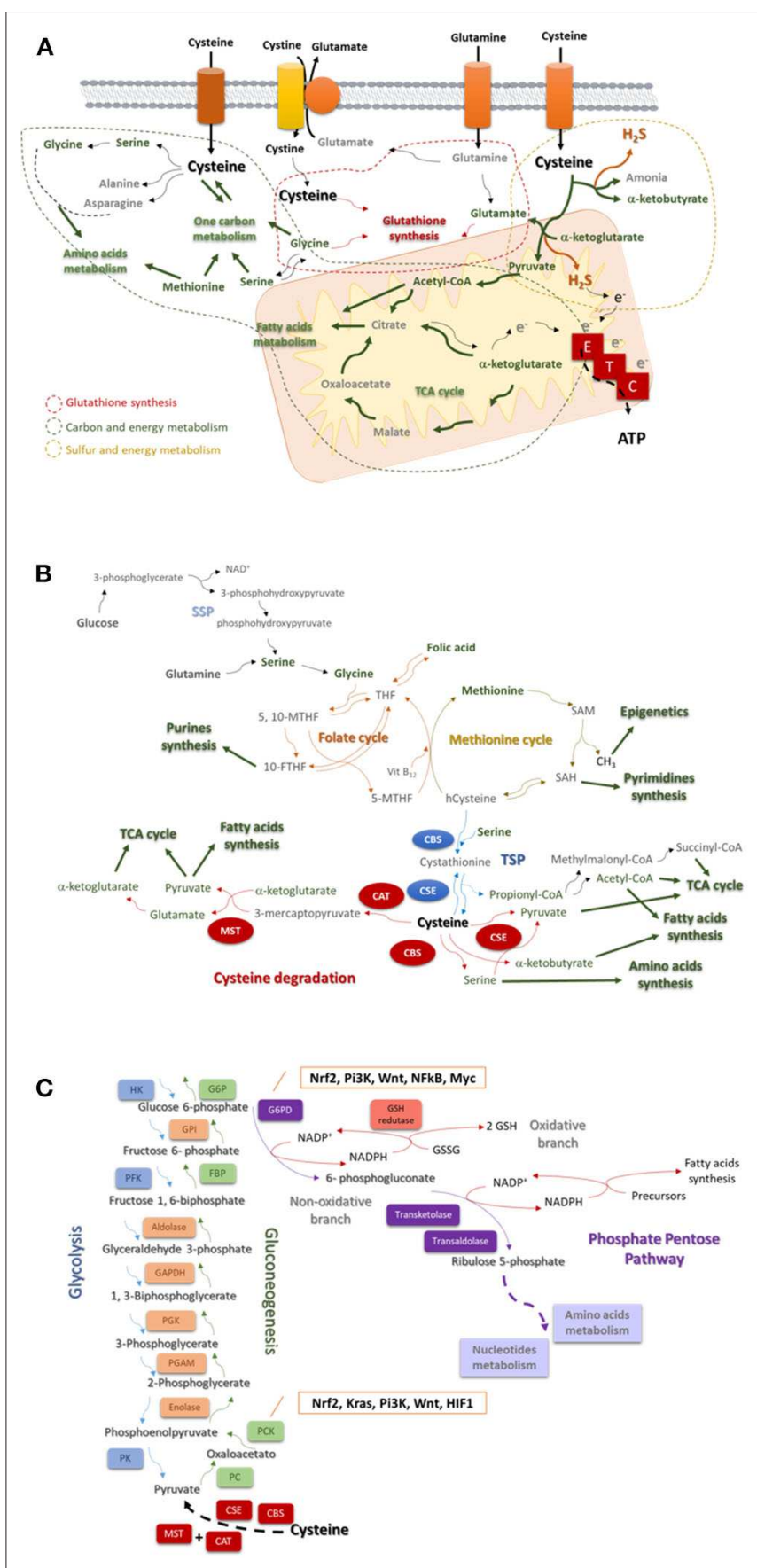

FIGURE 1 | Cysteine is a core player in the cellular metabolism. (A) Cysteine is imported as cystine or as cysteine. Cysteine plays a pivotal role in cancer: it is incorporated in glutathione, a reactive oxygen species (ROS) scavenger; upon degradation in cytosol or in mitochondria, it supplies carbon and energy metabolism through FA and AA syntheses, tricarboxylic acid (TCA) cycle, one carbon metabolism and the production of ATP through the ETC, and it contributes for sulfur and energy production as a generator of hydrogen sulfide $\left(\mathrm{H}_{2} \mathrm{~S}\right)$, a donor of electrons $\left(\mathrm{e}^{-}\right)$to ETC. (B) The one carbon metabolism is composed by the folate cycle and the methionine cycle. Serine, needed to start the folate cycle, can be glucose (serine synthesis pathway-SSP) or glutamine-originated. Serine originates glycine, which reacts with folic acid-derived tetrahydrofolate (THF), originating 5 ,

10-methylenetetrahydrofolate (5, 10-MTHF), which is converted into 
FIGURE 1 | 5-methyltetrahydrofolate (5-MTHF) or 10-methyltetrahydrofolate (10-MTHF). 5-FTHF reacts with vitamin $\mathrm{B}_{12}\left(\mathrm{Vit}_{12} \mathrm{~B}_{12}\right.$ ) and homocysteine (hCysteine), forming THF and methionine. 10-FTHF is incorporated in the synthesis of purines, essential for nucleotides synthesis. In the methionine cycle, methionine is converted sequentially into S-adenosylmethionine (SAM), and to S-adenosylhomocysteine (SAH). The consequent release of a methyl group $\left(\mathrm{CH}_{3}\right)$ will supply the methylation of DNA, DNA and histones. SAH is converted into hCysteine keeping on the methionine cycle, or it is deviated to the pyrimidines synthesis and consequently to nucleotides synthesis. Cysteine is de novo synthesized in the transsulfuration pathway (TSP), linking cysteine to the methionine cycle. The hCysteine, is converted into cystathionine through the condensation with serine. Cystathionine is hydrolyzed to cysteine and other organic compounds (e.g., $\alpha$-ketoglutarate or propionate). Cysteine can be degraded and originate (directly or not) pyruvate, $\alpha$-glutarate, $\alpha$-ketobutyrate, serine, propionyl-CoA, succinate, and acetyl-CoA to supply the tricarboxylic acid (TCA) cycle, amino acids synthesis or the fatty acids synthesis. (C) Glycolysis is the degradation of a glucose molecule into 2 pyruvate molecules, through a sequence of reactions, having three irreversible steps catalyzed by hexokinase (HK), phosphofructokinase (PFK), and pyruvate kinase (PK). Gluconeogenesis is almost a reversion of glycolysis and cysteine-derived pyruvate is converted in glucose. The reversible steps are common to glycolysis and gluconeogenesis and are catalyzed by enolase, phosphoglycerate mutase (PGAM), phosphoglycerate kinase (PGK),

Glyceraldehyde 3-phosphate dehydrogenase (GAPDH), aldolase, and Glucose-6-phosphate isomerase (GPI). The three irreversible steps of glycolysis impose gluconeogenesis to use four other enzymes: PC, pyruvate carboxylase; PKC, phosphoenolpyruvate carboxykinase; FBP, fructose 1,6-bisphosphatase; and G6PC, glucose 6-phosphatase. Gluconeogenesis is regulated by Nrf2, Kras, Pi3K, Wnt, and HIF1. Besides being an intermediate of glycolysis and gluconeogenesis glucose 6-phosphate is the substrate of phosphate pentose pathway (PPP), which has two biochemical branches (an oxidative and a non-oxidative branch) of reversible reactions. The non-oxidative branch of PPP uses glucose-6-phosphate to generate ribulose5-phosphate for $\mathrm{AA}$ and nucleotides synthesis. While the oxidative branch of PPP generates NADPH, involving the action of glutathione (GSH) reductase and the interplay with reductive biosynthesis, namely FA synthesis. PPP is regulated by Nrf2, Pi3K, Wnt, NFkB, and Myc.

The folate cycle depends on the dietary folate and controls the systemic levels of methionine and homocysteine (53), which directly regulates cysteine bioavailability. This cycle uses glycine and tetrahydrofolate (THF; converted from folic acid) and produces intermediates $[5,10$-methylene-tetrahydrofolate $(5,10$ MTHF) and 5-methylene-tetrahydrofolate (5-MTHF)] to supply purine synthesis and afterwards by the entrance of cobalamin (vitamin $\mathrm{B}_{12}$ ) and the interconnection with the methionine cycle, folic acid is again synthesized (Figure 1B).

The import of methionine is a vital step in one carbon metabolism, since methionine is an essential amino acid (AA), which is sequentially converted into S-adenosylmethionine (SAM) and S-adenosylhomocysteine (SAH), releasing methyl groups $\left(\mathrm{CH}_{3}\right)$ that will be used in DNA, RNA, and histones methylation (Figure 1B). SAH can be deviated to originate pyrimidines or originate homocysteine, which will react with vitamin $\mathrm{B}_{12}$ and 5 -MTHF in order to resynthesize methionine. Homocysteine can be deviated from one carbon metabolism and, together with serine, enter in TSP to originate cysteine and propionyl-CoA under the action of CBS and CSE $(21,54)$. Propionyl-CoA can be further converted into AA, fatty acids (FA) and TCA cycle intermediates $(22,23)$.

Methionine scarcity impairs cancer cells' proliferation (55), and methionine dependency is controlled by PI3K/AKT/mTOR pathway through the induction of the expression of cyst(e)ine/glutamate antiporter xc- (xCT; SLC7A11 gene) (56), ensuring that the levels of cysteine won't limit the bioavailability of methionine, since cysteine uptake downregulates TSP.

As above mentioned, the methyl groups generated in the onecarbon metabolism, when released from methionine cycle, are crucial for DNA, RNA, and histones methylation for epigenetic modulation (57), whose functioning is regulated by PI3K/mTOR and HIF $2 \alpha$ pathways, the same that control SSP and one-carbon metabolism $(58,59)$. Hence, the expression of LAT1 (SLC7A5), the main transporter of methionine, is associated with the activity of methyltransferases in lung cancer cells (60). Moreover, the relevance of one carbon metabolism is also highlighted by the association between the levels of folate in peripheral blood, DNA methylation and colorectal tumor staging (61). Accordingly, the existence of polymorphisms and the increased expression or activity of enzymes participating in one-carbon metabolism are considered markers for highly proliferative and aggressive cancer phenotypes and chemoresistance $(57,62,63)$.

\section{Cysteine Contribution for Gluconeogenesis and Phosphate Pentose Pathway (PPP)}

Gluconeogenesis or the synthesis of glucose from non-glucidic compounds, such as glycerol, lactate, pyruvate, acetyl-CoA, or glucogenic AA, only recently started to be explored in cancer. Gluconeogenesis (Figure 1C) is a reversion of glycolysis, with 3 alternative reactions counteracting the 3 irreversible steps of glycolysis (64-67). Cysteine is a glucogenic AA, as it originates pyruvate, however, as far as I know, cysteine was not yet explored as a source of glucose in cancer. Nevertheless, in other biological models cysteine has been pointed out as an important regulator of enzymes, such as peroxidases that can interact with PK and block the conversion of pyruvate into acetyl-CoA, avoiding pyruvate entrance in TCA cycle or in FA synthesis (68) and favoring its deviation into gluconeogenesis, ensuring the cell needs of glucose.

Gluconeogenic enzymes are regulated by signaling pathways pivotal in carcinogenesis KRAS-dependent, PIK3/mTOR and Wnt pathways and HIF1 [as reviewed in (69) and in (70)]. The pro-survival character of gluconeogenesis is supported by the upregulation or the de novo expression of its enzymes in different cancer types, such as breast, colon, stomach, uterine cervix, liver, and pancreas (67).

The inhibition of the final step of gluconeogenesis redirects glucose 6-phosphate to phosphate pentose pathway (PPP) (Figure 1C), making gluconeogenesis a supplier of PPP in glucose depleted environments. Again, cysteine as a source of pyruvate can be at the origin of glucose-6-phosphate canalized to PPP.

The PPP occurs in parallel to glycolysis through two irreversible oxidative reactions followed by two biochemical branches (an oxidative and a non-oxidative branch) of reversible reactions (71). The non-oxidative branch of PPP (Figure 1C) uses glucose-6-phosphate to generate pentose phosphates for $\mathrm{AA}$ and nucleotides synthesis. While the oxidative branch of PPP generates NADPH, essential for FA synthesis and 
redox balance (72-75). Indeed, a cellular dependence on PPP was described in cancer cells that are heavy cystine importers, requiring NADPH for cystine to cysteine intracellular conversion (76).

PPP is associated with increased cancer cell survival and proliferation $(74,77)$, implying the inhibition of phosphofructokinase (mainly PFK1) from glycolysis $(78,79)$, a direct competitor of glucose-6-phosphate dehydrogenase (G6PD), the limiting enzyme in PPP (75). PI3K/AKT pathway controls the expression and the activity of G6PD, whose dimerization is activated by phosphorylation (80). Wnt/c-MYC and p65-NFkB pathways induce the expression of G6PD, activating PPP as part of a more metastatic and chemoresistant cancer phenotype $(81,82)$.

Besides cysteine is a source of pyruvate, another important link of gluconeogenesis and PPP to cysteine metabolism and antioxidant character (83), is the fact that the expression of PCK1 (phosphoenolpyruvate carboxykinase 1) and G6PD is directly regulated by $\mathrm{Nrf} 2$, a master regulator of redox control $(84,85)$.

\section{Regulation of Cysteine Anabolism and Catabolism, in Cancer}

The metabolic reliance on cysteine is a common feature to different cancer types. Therefore, the upregulation of catabolic pathways and the expression of cyst(e)ine transporters is often observed in cancer together with the upregulation of cysteine synthesis. The TSP is dependent on the action of CBS and CSE, which can also act in cysteine catabolism (Figure 1B). The expression of CBS and CSE seems to be cancer type-related often dependent on the organ and the genetic background.

In ovaries, it seems that CSE must be silenced upon malignant transformation, since it is expressed in normal epithelial ovarian cells but it is absent in malignant tumors $(27,86)$. On the contrary, the high CBS expression is a feature of ovarian cancer, being associated with advanced stage and chemoresistance (27, 86). In colon cancer, the increased expression and activity of CBS and CSE is associated with high rates of proliferation and migration of cancer cells, controlled, respectively, by PI3K/AKT and Wnt pathways $(28,86,87)$. Controversially to the evidence that CBS is linked to carcinogenesis, a study presents CBS as a tumor suppressor gene, claiming that in gastric and colorectal cancer the expression of CBS is inhibited by DNA methylation in association with KRAS mutations (88). Notwithstanding a study reporting the importance of both CBS and CSE in gastric carcinogenesis (89), other study shows a compensatory mechanism involving the two enzymes. It was demonstrated that CSE expression overlaps the absence of CBS, being CSE correlated to increased proliferation and decreased apoptotic rate (41). In thyroid cancer, CBS is the major responsible for $\mathrm{H}_{2} \mathrm{~S}$ production, which activates cancer cells proliferation and migration, through ROS/PI3K/AKT/mTOR and MAPK pathways (90). In breast cancer, tumors, and cell lines, CSE favors cell proliferation and migration under the command of STAT3, a member of JAK/STAT pathway (38); while in a murine model, CSE is stated as controlling the metastatic behavior of breast cancer cells through VEGF-dependent PI3K and MAPK pathways (91). In melanoma, CSE loss of expression accompanies the progression of the disease, being highly expressed in primary tumors and low expressed in metastatic lesions (30). The abovementioned data supports that the role of CBS and CSE enzymes, favoring or counteracting cancer, is highly adaptive and obviously dependent on the cysteine bioavailability itself, within certain cancer microenvironmental and metabolic contexts. Furthermore, if the role of CBS and CSE in cancer is related to cysteine anabolism or catabolism is not always clear.

Cysteine degradation catalyzed by CAT and MST (Figure 1B) is not deeply explored in cancer, since MST is more enzymatically efficient at a $\mathrm{pH}$ higher than the physiological, thus the role of CBS and CSE is considered more relevant in cancer biology (92). However, Zuhra et al. (93) demonstrated recently, in a colon cancer cell line, that MST can produce $\mathrm{H}_{2} \mathrm{~S}$ from $\mathrm{N}$-acetylcysteine instead of cysteine-derived 3-mercaptopyruvate. Nonetheless, MST is constitutively expressed in normal differentiated cells and some studies have detected its expression or activity in various cancer cell lines and primary tumors, including brain, colon, liver, kidney, lung and bladder cancer, and melanoma [reviewed in (35)]. In some of those studies the MST expression was higher than CSE expression (94, 95), and an association between MST expression and chemoresistance was found (96, 97). Few functional assays tried to correlate the expression and/or activity of MST with the cancer cells features, however, using inhibiting and silencing assays, some studies proved that MST activity is important for cancer cells proliferation (98, 99). Unfortunately, most studies addressing cysteine degradation are focused in $\mathrm{H}_{2} \mathrm{~S}$ production and not in resulting organic compounds.

\section{REGULATORS AND MEDIATORS OF CYSTEINE TRANSPORT, IN CANCER}

The transport of cysteine across the cell membrane is a critical step in cysteine metabolic course (Figure 1), and it is often transported in its oxidized dimer, cystine. Amongst cystine transporters, the cystine/glutamate antiporters are the most studied in cancer context, but mainly on their role in glutamate export $(100,101)$, showing a correlation between glutamate export and increased cancer cells aggressiveness (100, 102106). However, for glutamate export to occur cystine import is mandatory, thus the increased intracellular levels of cysteine must be relevant for cancer poor prognosis. This evidence is reinforced by the activation of cysteine endogenous synthesis $(56,107)$ in cancer cells upon xCT downregulation (108-110).

$\mathrm{xCT}$ is an undeniable linker between cysteine and the whole metabolic network. Cancer cells overexpressing xCT present an overactivation of the glucose-dependent PPP, as a mean of replacing NADPH consumed in the imperative conversion of cystine into cysteine (76). Furthermore, xCT makes a bridge between cysteine uptake and glutamine metabolism, since glutamine is the main precursor of glutamate, whose export is essential for xCT-mediated import of cysteine (17). The role of $\mathrm{xCT}$, as a facilitator of cyst(e)ine protective antioxidant role 


\section{Cyst(e)ine Rich Microenvironment}
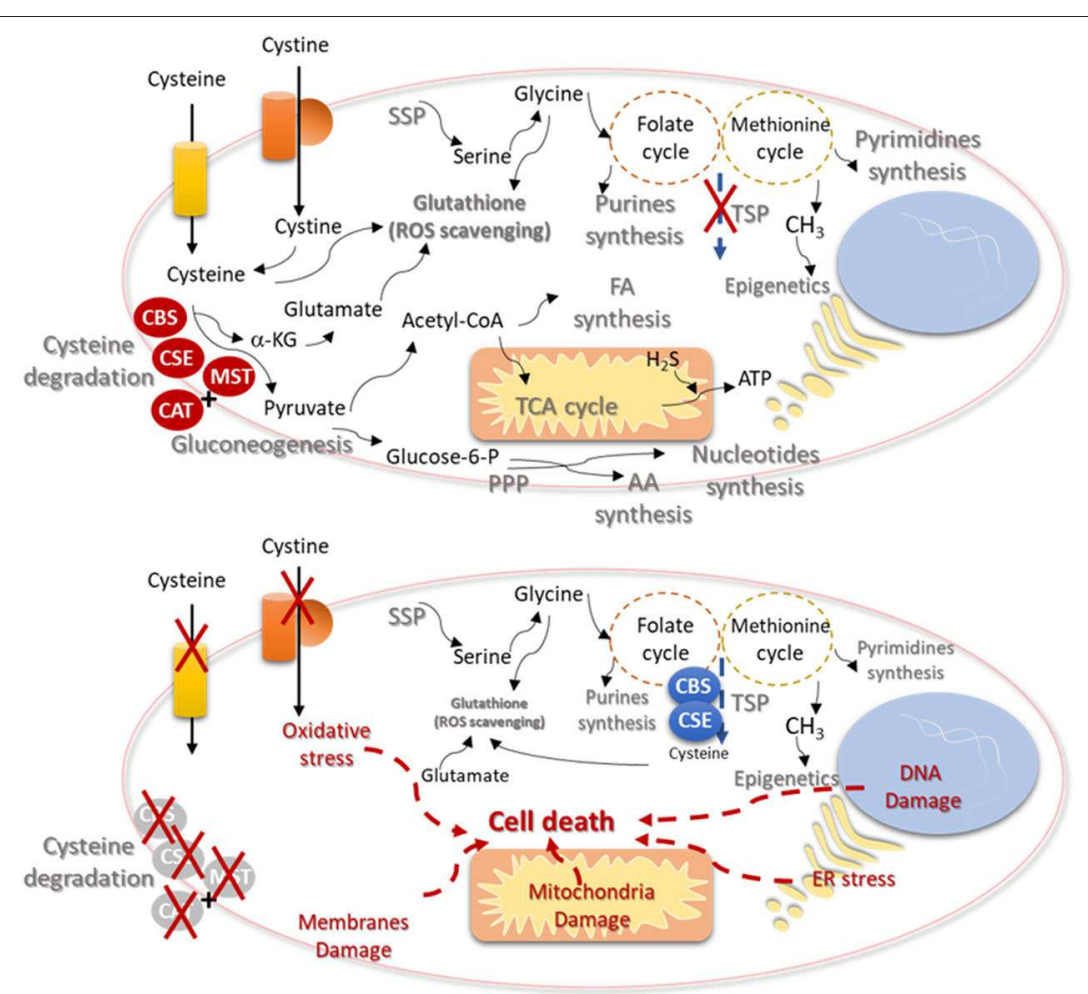

FIGURE 2 | Cysteine transport and catabolism ensures cell functioning- new cues on metabolism based therapies. In a cyst(e)ine rich tumor microenvironment, cancer cells express high levels of cyst(e)ine transporters and the catabolism of cysteine is activated by the action of cystathionine $\beta$-synthase (CBS); cystathionine $\gamma$-lyase (CSE), or 3-mercapto-pyruvate sulfurtransferase (MST), which works together with cysteine aminotransferase (CAT). De novo synthesis of cysteine (transsulfuration pathway-TSP) will be diminished and the syntheses of serine (serine synthesis pathway - SSP) and glycine will supply the one-carbon metabolism (folate and methionine cycles), in order to support the synthesis of nucleotides and methyl groups, respectively, needed for cell proliferation and epigenetic regulation. Serine-derived glycine together with cysteine and glutamate constitute the glutathione molecule, crucial for the maintenance of the redox state needed for cellular metabolic functioning. Glutamate itself can be cysteine-derived, since $\alpha$-ketoglutarate ( $\alpha-\mathrm{KG}$ ) results from cysteine degradation and is directly converted into glutamate. Cysteine as a source of pyruvate contributes for biomass production, through the TCA cycle and the syntheses of FA and AA. Cysteine-derived pyruvate can be a substrate to produce glucose through gluconeogenesis, making a bridge between cysteine and glucose-dependent pathways, as phosphate pentose pathway (PPP). Electron donors generated in the metabolic pathways and cysteine-derived $\mathrm{H}_{2} \mathrm{~S}$ contributes to oxidative phosphorylation and ATP production. The inhibition of cysteine uptake and catabolism will affect the metabolic pathways dependent on cysteine. TSP will be activated but without the uptake of cysteine, the ability to maintain the glutathione levels and reactive oxygen species (ROS) scavenging capacity will be decreased. The augment of the oxidative stress will induce DNA, membranes and mitochondria damages and endoplasmic reticulum (ER) stress. Ultimately cell injury and death will be triggered.

in cancer cells, is evidenced by the regulation of its expression by Nrf2 (111) and by signaling pathways activated by oxidative stress, including PI3K/AKT/mTOR $(56,112,113)$ and MAPK pathways (110). Since augmented glutathione contributes for chemoresistance, the expression of $\mathrm{xCT}$ is also associated with resistance to drugs, platinum-salts (9) and epigenetic modulators (114), and with cell death evasion $(115,116)$. Considering a new cell death process, called ferroptosis, $\mathrm{xCT}$ is an important inhibitor, since the accumulation of lipid peroxides activates ferroptosis and cysteine-derived glutathione is the substrate used by glutathione peroxidase 4 (GPX4) in the dissipation of lipids peroxides (117).

The cysteine direct import (118) is mediated by cysteine transporters, and the expression of some of them have been addressed in cancer. Albeit, the promiscuity of these transporters in transferring different AA (e.g., cysteine, glutamine, and glutamate) impedes the direct association between their overexpression and cysteine uptake. Even though, their expression is relevant in cancer as it happens with AT- $\mathrm{B}^{0,+}$ (SLC6A14), which is the transporter with the broadest selectivity for AA, including cysteine (119-123).

In brief, EAAT3 (SLC1A1) overexpression was detected in brain and prostate cancer cells (124-126), being associated with increased chemoresistance in colorectal cancer models (127). As mentioned above, LAT1 can affect the bioavailability of cysteine since it is the main methionine transporter, being its expression related to chemoresistance (128). ASCT1 (SLC1A4) is overexpressed in prostate cancer (129), however, its expression and relevance in cancer was addressed considering glutamine or glutamate transport. Because glutamine/glutamate and cysteine metabolic pathways are deeply connected $(130,131)$ and cysteine is also considered a modulator of glutamine transport $(132,133)$, certainly these transporters are crucial in the cysteine metabolism reliance of cancer cells. 


\section{DISCUSSION}

The increased intracellular bioavailability of cysteine is itself a stimulus for metabolic remodeling. Considering the role of cysteine as a carbon source in a scenario of high concentrations of cysteine, with no limitation in cyst(e)ine uptake, most part of cysteine will enter the degradation route, reducing the need for cysteine synthesis, dependent on the deviation of homocysteine from the one-carbon metabolism (Figure 2). This would imply the accumulation of serine that is very important for glycine synthesis and the activity of folate and methionine cycles, in order to supply the synthesis of nucleotides and methyl groups, respectively, needed for cell proliferation and epigenetic regulation. Serine-derived glycine together with cysteine and glutamate constitute the glutathione molecule, essential for the maintenance of the redox state allowing cellular metabolic functioning and chemoresistance. Glutamate can be a product of cysteine conversion into pyruvate, with $\alpha$-ketoglutarate consume. Further, glutamate can be converted into glutamine, which is considered the main substitute of glucose (134).

Cysteine as a source of pyruvate can liberate the cell from the dependency of glucose, and contribute for biomass production, through the TCA cycle and the syntheses of FA and AA. As aforementioned, cysteine-derived pyruvate can be a substrate to produce glucose, making a bridge between cysteine and glucose-dependent pathways, as glycolysis and PPP. All the metabolic pathways that generate electron donors participating in the oxidative phosphorylation can be supplied by cysteine. In another hand, cysteine degradation releases $\mathrm{H}_{2} \mathrm{~S}$, which is itself an electron donor for ETC.

In brief, cysteine metabolic route is full of cues to find biomarkers for prognosis, recurrence and response to therapy, as well as suitable therapeutic targets to trigger cancer cell death due to cysteine starvation (Figure 2), as pointed out in different papers $(135,136)$. In certain type of cancer, it

\section{REFERENCES}

1. Nunes SC, Lopes-Coelho F, Gouveia-Fernandes S, Ramos C, Pereira SA, Serpa J. Cysteine boosters the evolutionary adaptation to $\mathrm{CoCl}(2)$ mimicked hypoxia conditions, favouring carboplatin resistance in ovarian cancer. BMC Evol Biol. (2018) 18:97. doi: 10.1186/s12862-018-1214-1

2. Nunes SC, Ramos C, Lopes-Coelho F, Sequeira CO, Silva F, GouveiaFernandes S, et al. Cysteine allows ovarian cancer cells to adapt to hypoxia and to escape from carboplatin cytotoxicity. Sci Rep. (2018) 8:9513. doi: 10.1038/s41598-018-27753-y

3. Lopes-Coelho F, Gouveia-Fernandes S, Gonçalves LG, Nunes C, Faustino I, Silva F, et al. HNF1 $\beta$ drives glutathione (GSH) synthesis underlying intrinsic carboplatin resistance of ovarian clear cell carcinoma (OCCC). Tumor Biol. (2016) 37:4813-29. doi: 10.1007/s13277-015-4290-5

4. Colla R, Izzotti A, De Ciucis C, Fenoglio D, Ravera S, Speciale $\mathrm{A}$, et al. Glutathione-mediated antioxidant response and aerobic metabolism: two crucial factors involved in determining the multidrug resistance of high-risk neuroblastoma. Oncotarget. (2016) 7:70715-37. doi: 10.18632/oncotarget.12209

5. Zanotto-Filho A, Masamsetti VP, Loranc E, Tonapi SS, Gorthi A, Bernard X, et al. Alkylating agent-induced NRF2 blocks endoplasmic reticulum stress-mediated apoptosis via control of glutathione pools may be an unsuccessful strategy, since many cancer cells upon cysteine scarcity or the inhibition of cys(e)ine transport can upregulate TSP for endogenous cysteine production $(137,138)$. However, the need of methyl groups for epigenetic regulation, in some tumors, prevents the activation of cysteine synthesis and activates one-carbon metabolism (138). Therefore, the systemic decrease of cysteine levels is proposed as a suitable strategy in cancer clinical management, being supported by pre-clinical studies with promising results in breast and prostate carcinomas and leukemia. These studies showed that systemic treatment with cyst(e)inase decreases the levels of cysteine together with tumor burden (139). Cyst(e)inase degrades extracellular cysteine and cystine, leading to reduced intracellular cysteine and glutathione levels, affecting cancer cells redox capacity (44, 140 ), inducing the accumulation of ROS (26) and consequent ferroptosis $(135,136)$.

This review has also the objective of highlighting that efforts must be made to clarify the actual role of cysteine catabolism in cancer biosynthesis and bioenergetics, beyond $\mathrm{H}_{2} \mathrm{~S}$ production. Cysteine catabolism may not be a core metabolic pathway but deviation of cysteine-derived compounds into other metabolic pathways is pivotal in cancer cells metabolic drift and survival.

\section{AUTHOR CONTRIBUTIONS}

The author confirms being the sole contributor of this work and has approved it for publication.

\section{FUNDING}

This research lab was funded by iNOVA4HealthUID/Multi/04462/ a program financially supported by Fundação para a Ciência e a Tecnologia-Ministério da Educação e Ciência (FCT-MCTES), through national funds and co-funded by FEDER under the PT2020 Partnership Agreement. and protein thiol homeostasis. Mol Cancer Ther. (2016) 15:300014. doi: 10.1158/1535-7163.MCT-16-0271

6. Lien EC, Lyssiotis CA, Juvekar A, Hu H, Asara JM, Cantley LC, et al. Glutathione biosynthesis is a metabolic vulnerability in $\mathrm{PI}(3) \mathrm{K} /$ Akt-driven breast cancer. Nat Cell Biol. (2016) 18:572-8. doi: 10.1038/ncb3341

7. Harris Isaac S, Treloar Aislinn E, Inoue S, Sasaki M, Gorrini C, Lee Kim C, et al. Glutathione and Thioredoxin Antioxidant Pathways Synergize To Drive Cancer Initiation And Progression. Cancer Cell. (2015) 27:21122. doi: 10.1016/j.ccell.2014.11.019

8. Traverso N, Ricciarelli R, Nitti M, Marengo B, Furfaro AL, Pronzato MA, et al. Role of glutathione in cancer progression and chemoresistance. Oxid Med Cell Longev. (2013) 2013:972913-. doi: 10.1155/2013/972913

9. Okuno S, Sato H, Kuriyama-Matsumura K, Tamba M, Wang H, Sohda $\mathrm{S}$, et al. Role of cystine transport in intracellular glutathione level and cisplatin resistance in human ovarian cancer cell lines. Br J Cancer. (2003) 88:951-6. doi: 10.1038/sj.bjc.6600786

10. Ballatori N, Krance SM, Notenboom S, Shi S, Tieu K, Hammond CL. Glutathione dysregulation and the etiology and progression of human diseases. Biol Chem. (2009) 390:191-214. doi: 10.1515/BC.2009.033

11. Wu G, Fang Y-Z, Yang S, Lupton JR, Turner ND. Glutathione metabolism and its implications for health. J Nutr. (2004) 134:48992. doi: $10.1093 /$ jn/134.3.489 
12. Wang W, Ballatori N. Endogenous glutathione conjugates: occurrence and biological functions. Pharmacol Rev. (1998) 50:335-56.

13. Kalinina EV, Chernov NN, Novichkova MD. Role of glutathione, glutathione transferase, and glutaredoxin in regulation of redox-dependent processes. Biochem Biokhimiia. (2014) 79:1562-83. doi: 10.1134/S0006297914130082

14. Sosa V, Moline T, Somoza R, Paciucci R, Kondoh H, Lleonart ME. Oxidative stress and cancer: an overview. Ageing Res Rev. (2013) 12:37690. doi: 10.1016/j.arr.2012.10.004

15. Postovit L, Widmann C, Huang P, Gibson SB. Harnessing oxidative stress as an innovative target for cancer therapy. Oxid Med Cell Longev. (2018) 2018:6135739. doi: 10.1155/2018/6135739

16. Prasad S, Srivastava SK. Oxidative stress and cancer: chemopreventive and therapeutic role of triphala. Antioxidants. (2020) 9:72. doi: 10.3390/antiox9010072

17. Serpa J. Metabolic remodeling as a way of adapting to tumor microenvironment (TME), a job of several holders. Adv Exp Med Biol. (2020) 1219:1-34. doi: 10.1007/978-3-030-34025-4_1

18. Lin X, Xiao Z, Chen T, Liang SH, Guo H. Glucose metabolism on tumor plasticity, diagnosis, and treatment. Front Oncol. (2020) 10:317. doi: 10.3389/fonc.2020.00317

19. Zou S, Shimizu T, Shimizu S, Higashi Y, Nakamura K, Ono H, et al. Possible role of hydrogen sulfide as an endogenous relaxation factor in the rat bladder and prostate. Neurourol Urodyn. (2018) 37:2519-26. doi: 10.1002/nau.23788

20. Huang $\mathrm{CW}$, Moore $\mathrm{PK} . \mathrm{H}_{2} \mathrm{~S}$ synthesizing enzymes: biochemistry and molecular aspects. In: Moore PK, Whiteman M, editors. Chemistry, Biochemistry and Pharmacology of Hydrogen Sulfide. Cham: Springer International Publishing (2015). p. 3-25. doi: 10.1007/978-3-319-18144-8_1

21. Pascale RM, Peitta G, Simile MM, Feo F. Alterations of methionine metabolism as potential targets for the prevention and therapy of hepatocellular carcinoma. Medicina. (2019) 55:296. doi: 10.3390/medicina55060296

22. Longo N, Price LB, Gappmaier E, Cantor NL, Ernst SL, Bailey C, et al. Anaplerotic therapy in propionic acidemia. Mol Genet Metab. (2017) 122:519. doi: 10.1016/j.ymgme.2017.07.003

23. Adeva-Andany MM, López-Maside L, Donapetry-García C, Fernández-Fernández C, Sixto-Leal C. Enzymes involved in branchedchain amino acid metabolism in humans. Amino Acids. (2017) 49:1005-28. doi: 10.1007/s00726-017-2412-7

24. Wang R. Physiological implications of hydrogen sulfide: a whiff exploration that blossomed. Physiol Rev. (2012) 92:791896. doi: 10.1152/physrev.00017.2011

25. Liu M, Wu L, Montaut S, Yang G. Hydrogen sulfide signaling axis as a target for prostate cancer therapeutics. Prostate Cancer. (2016) 2016:9. doi: 10.1155/2016/8108549

26. Nunes SC, Serpa J. Glutathione in ovarian cancer: a double-edged sword. Int J Mol Sci. (2018) 19:1882. doi: 10.3390/ijms19071882

27. Bhattacharyya S, Saha S, Giri K, Lanza IR, Nair KS, Jennings NB, et al. Cystathionine beta-synthase (CBS) contributes to advanced ovarian cancer progression and drug resistance. PLoS ONE. (2013) 8:e79167. doi: 10.1371/journal.pone.0079167

28. Szabo C, Coletta C, Chao C, Módis K, Szczesny B, Papapetropoulos A, et al. Tumor-derived hydrogen sulfide, produced by cystathionine- $\beta$-synthase, stimulates bioenergetics, cell proliferation, and angiogenesis in colon cancer. Proc Natl Acad Sci USA. (2013) 110:12474-9. doi: 10.1073/pnas.1306241110

29. Sen S, Kawahara B, Gupta D, Tsai R, Khachatryan M, Roy-Chowdhuri S, et al. Role of cystathionine $\beta$-synthase in human breast cancer. Free Radic Biol Med. (2015) 86:228-38. doi: 10.1016/j.freeradbiomed.2015.05.024

30. Panza E, De Cicco P, Armogida C, Scognamiglio G, Gigantino V, Botti $\mathrm{G}$, et al. Role of the cystathionine $\gamma$ lyase/hydrogen sulfide pathway in human melanoma progression. Pigment Cell Melanoma Res. (2015) 28:6172. doi: $10.1111 /$ pcmr.12312

31. Gai J-W, Qin W, Liu M, Wang H-F, Zhang M, Li M, et al. Expression profile of hydrogen sulfide and its synthases correlates with tumor stage and grade in urothelial cell carcinoma of bladder. Urol Oncol Semi Original Investig. (2016) 34:166.e15-e20. doi: 10.1016/j.urolonc.2015.06.020

32. Pan Y, Zhou C, Yuan D, Zhang J, Shao C. Radiation exposure promotes hepatocarcinoma cell invasion through epithelial mesenchymal transition mediated by $\mathrm{H}_{2}$ S/CSE pathway. Radiat Res. (2015) 185:96105. doi: $10.1667 / R R 14177.1$

33. Módis K, Panopoulos P, Coletta C, Papapetropoulos A, Szabo C. Hydrogen sulfide-mediated stimulation of mitochondrial electron transport involves inhibition of the mitochondrial phosphodiesterase 2A, elevation of cAMP and activation of protein kinase A. Biochem Pharmacol. (2013) 86:13119. doi: 10.1016/j.bcp.2013.08.064

34. Fu M, Zhang W, Wu L, Yang G, Li H, Wang R. Hydrogen sulfide $\left(\mathrm{H}_{2} \mathrm{~S}\right)$ metabolism in mitochondria and its regulatory role in energy production. Proc Natl Acad Sci USA. (2012) 109:2943-8. doi: 10.1073/pnas.1115634109

35. Augsburger F, Szabo C. Potential role of the 3-mercaptopyruvate sulfurtransferase (3-MST)-hydrogen sulfide $\left(\mathrm{H}_{2} \mathrm{~S}\right)$ pathway in cancer cells. Pharmacol Res. (2020) 154:104083. doi: 10.1016/j.phrs.2018.11.034

36. Giuffrè A, Vicente JB. Hydrogen sulfide biochemistry and interplay with other gaseous mediators in mammalian physiology. Oxid Med Cell Longev. (2018) 2018:6290931. doi: 10.1155/2018/6290931

37. Wang L, Shi H, Zhang X, Zhang X, Liu Y, Kang W, et al. I157172, a novel inhibitor of cystathionine gamma-lyase, inhibits growth and migration of breast cancer cells via SIRT1-mediated deacetylation of STAT3. Oncol Rep. (2019) 41:427-36. doi: 10.3892/or.2018.6798

38. You J, Shi X, Liang H, Ye J, Wang L, Han H, et al. Cystathionine- $\gamma$ lyase promotes process of breast cancer in association with STAT3 signaling pathway. Oncotarget. (2017) 8:65677-86. doi: 10.18632/oncotarget.20057

39. Turbat-Herrera EA, Kilpatrick MJ, Chen J, Meram AT, Cotelingam J, Ghali G, et al. Cystathione $\beta$-synthase is increased in thyroid malignancies. Anticancer Res. (2018) 38:6085-90. doi: 10.21873/anticanres.12958

40. Alix-Panabières C, Cayrefourcq L, Mazard T, Maudelonde T, Assenat E, Assou S. Molecular portrait of metastasis-competent circulating tumor cells in colon cancer reveals the crucial role of genes regulating energy metabolism and DNA repair. Clin Chem. (2017) 63:700-13. doi: 10.1373/clinchem.2016.263582

41. Sekiguchi F, Sekimoto T, Ogura A, Kawabata A. Endogenous hydrogen sulfide enhances cell proliferation of human gastric cancer AGS cells. Biol Pharm Bull. (2016) 39:887-90. doi: 10.1248/bpb.b15-01015

42. Poisson LM, Munkarah A, Madi H, Datta I, Hensley-Alford S, Tebbe C, et al. A metabolomic approach to identifying platinum resistance in ovarian cancer. J Ovarian Res. (2015) 8:13. doi: 10.1186/s13048-015-0140-8

43. Pérez-Miguelsanz J, Vallecillo N, Garrido F, Reytor E, Pérez-Sala D, Pajares MA. Betaine homocysteine S-methyltransferase emerges as a new player of the nuclear methionine cycle. Biochim Biophys Acta Mol Cell Res. (2017) 1864:1165-82. doi: 10.1016/j.bbamcr.2017.03.004

44. Combs JA, DeNicola GM. The non-essential amino acid cysteine becomes essential for tumor proliferation and survival. Cancers. (2019) 11:678. doi: 10.3390/cancers 11050678

45. Kim YK, Hammerling $U$. The mitochondrial PKCdelta/retinol signal complex exerts real-time control on energy homeostasis. Biochim Biophys Acta Mol Cell Biol Lipids. (2020) 2020:158614. doi: 10.1016/j.bbalip.2020.158614

46. Yu L, Teoh ST, Ensink E, Ogrodzinski MP, Yang C, Vazquez AI, et al. Cysteine catabolism and the serine biosynthesis pathway support pyruvate production during pyruvate kinase knockdown in pancreatic cancer cells. Cancer Metab. (2019) 7:13. doi: 10.1186/s40170-019-0205-Z

47. DeBerardinis RJ. Serine metabolism: some tumors take the road less traveled. Cell Metab. (2011) 14:285-6. doi: 10.1016/j.cmet.2011.08.004

48. Amelio I, Cutruzzolá F, Antonov A, Agostini M, Melino G. Serine and glycine metabolism in cancer. Trends Biochem Sci. (2014) 39:1918. doi: 10.1016/j.tibs.2014.02.004

49. Labuschagne Christiaan F, van den Broek Niels JF, Mackay Gillian M, Vousden Karen H, Maddocks Oliver DK. Serine, but not glycine, supports one-carbon metabolism and proliferation of cancer cells. Cell Rep. (2014) 7:1248-58. doi: 10.1016/j.celrep.2014.04.045

50. Zhang B, Zheng A, Hydbring P, Ambroise G, Ouchida AT, Goiny M, et al. PHGDH defines a metabolic subtype in lung adenocarcinomas with poor prognosis. Cell Rep. (2017) 19:2289-303. doi: 10.1016/j.celrep.2017.05.067

51. Xian Y, Zhang S, Wang X, Qin J, Wang W, Wu H. Phosphoglycerate dehydrogenase is a novel predictor for poor prognosis in gastric cancer. Onco Targets Ther. (2016) 9:5553-60. doi: 10.2147/OTT.S105787 
52. Song Z, Feng C, Lu Y, Lin Y, Dong C. PHGDH is an independent prognosis marker and contributes cell proliferation, migration and invasion in human pancreatic cancer. Gene. (2018) 642:43-50. doi: 10.1016/j.gene.2017.11.014

53. Nazki FH, Sameer AS, Ganaie BA. Folate: metabolism, genes, polymorphisms and the associated diseases. Gene. (2014) 533:11-20. doi: 10.1016/j.gene.2013.09.063

54. Kulkarni A, Dangat K, Kale A, Sable P, Chavan-Gautam P, Joshi S. Effects of altered maternal folic acid, vitamin B12 and docosahexaenoic acid on placental global DNA methylation patterns in Wistar rats. PLoS ONE. (2011) 6:e17706. doi: 10.1371/journal.pone.0017706

55. Hens JR, Sinha I, Perodin F, Cooper T, Sinha R, Plummer J, et al. Methioninerestricted diet inhibits growth of MCF10AT1-derived mammary tumors by increasing cell cycle inhibitors in athymic nude mice. BMC Cancer. (2016) 16:349. doi: 10.1186/s12885-016-2404-0

56. Lien EC, Ghisolfi L, Geck RC, Asara JM, Toker A. Oncogenic PI3K promotes methionine dependency in breast cancer cells through the cystine-glutamate antiporter xCT. Sci Signal. (2017) 10:eaao6604. doi: 10.1126/scisignal.aao6604

57. Nilsson R, Nicolaidou V, Koufaris C. Mitochondrial MTHFD isozymes display distinct expression, regulation, and association with cancer. Gene. (2019) 716:144032. doi: 10.1016/j.gene.2019.144032

58. Green NH, Galvan DL, Badal SS, Chang BH, LeBleu VS, Long J, et al. MTHFD2 links RNA methylation to metabolic reprogramming in renal cell carcinoma. Oncogene. (2019) 38:6211-25. doi: 10.1038/s41388-019-0869-4

59. Zeng JD, Wu WKK, Wang HY, Li XX. Serine and one-carbon metabolism, a bridge that links mTOR signaling and DNA methylation in cancer. Pharmacol Res. (2019) 149:104352. doi: 10.1016/j.phrs.2019.104352

60. Dann SG, Ryskin M, Barsotti AM, Golas J, Shi C, Miranda M, et al. Reciprocal regulation of amino acid import and epigenetic state through Lat1 and EZH2. EMBO J. (2015) 34:1773-85. doi: 10.15252/embj.201488166

61. Ferrari A, Torrezan GT, Carraro DM, Aguiar Junior S. Association of folate and vitamins involved in the 1-carbon cycle with polymorphisms in the methylenetetrahydrofolate reductase gene (MTHFR) and global DNA methylation in patients with colorectal cancer. Nutrients. (2019) 11:1368. doi: 10.3390/nu11061368

62. Gustafsson Sheppard N, Jarl L, Mahadessian D, Strittmatter L, Schmidt A, Madhusudan N, et al. The folate-coupled enzyme MTHFD2 is a nuclear protein and promotes cell proliferation. Sci Rep. (2015) 5:15029. doi: $10.1038 /$ srep 15029

63. Zhang X, Tang J, Shen N, Ren K. A single-nucleotide polymorphism (rs1805087) in the methionine synthase (METH) gene increases the risk of prostate cancer. Aging. (2018) 10:2741-54. doi: 10.18632/aging.101584

64. Tsai WW, Matsumura S, Liu W, Phillips NG, Sonntag T, Hao E, et al. ATF3 mediates inhibitory effects of ethanol on hepatic gluconeogenesis. Proc Natl Acad Sci USA. (2015) 112:2699-704. doi: 10.1073/pnas.14246 41112

65. Potts A, Uchida A, Deja S, Berglund ED, Kucejova B, Duarte JA, et al. Cytosolic phosphoenolpyruvate carboxykinase as a cataplerotic pathway in the small intestine. Am J Physiol Gastrointest Liver Physiol. (2018) 315:G24958. doi: 10.1152/ajpgi.00039.2018

66. Zhang Y, Guan Q, Liu Y, Zhang Y, Chen Y, Chen J, et al. Regulation of hepatic gluconeogenesis by nuclear factor Y transcription factor in mice. J Biol Chem. (2018) 293:7894-904. doi: 10.1074/jbc.RA117.000508

67. Grasmann G, Smolle E, Olschewski H, Leithner K. Gluconeogenesis in cancer cells - repurposing of a starvation-induced metabolic pathway? Biochimica et Biophysica Acta Reviews Cancer. (2019) 1872:24-36. doi: 10.1016/j.bbcan.2019.05.006

68. Irokawa $\mathrm{H}$, Tachibana $\mathrm{T}$, Watanabe $\mathrm{T}$, Matsuyama $\mathrm{Y}$, Motohashi $\mathrm{H}$, Ogasawara A, et al. Redox-dependent regulation of gluconeogenesis by a novel mechanism mediated by a peroxidatic cysteine of peroxiredoxin. Sci Rep. (2016) 6:33536. doi: 10.1038/srep33536

69. Lao-On U, Attwood PV, Jitrapakdee S. Roles of pyruvate carboxylase in human diseases: from diabetes to cancers and infection. J Mol Med. (2018) 96:237-47. doi: 10.1007/s00109-018-1622-0

70. Wang Z, Dong C. Gluconeogenesis in cancer: function and regulation of PEPCK, FBPase, and G6Pase. Trends Cancer. (2019) 5:30-45. doi: 10.1016/j.trecan.2018.11.003
71. Ramos-Martinez JI. The regulation of the pentose phosphate pathway: remember Krebs. Arch Biochem Biophys. (2017) 614:50-2. doi: 10.1016/j.abb.2016.12.012

72. Pavlova NN, Thompson CB. The emerging hallmarks of cancer metabolism. Cell Metab. (2016) 23:27-47. doi: 10.1016/j.cmet.2015.12.006

73. Stincone A, Prigione A, Cramer T, Wamelink MM, Campbell K, Cheung $\mathrm{E}$, et al. The return of metabolism: biochemistry and physiology of the pentose phosphate pathway. Biol Rev Camb Philos Soc. (2015) 90:92763. doi: $10.1111 /$ brv. 12140

74. Patra KC, Hay N. The pentose phosphate pathway and cancer. Trends Biochem Sci. (2014) 39:347-54. doi: 10.1016/j.tibs.2014.06.005

75. Jin L, Zhou Y. Crucial role of the pentose phosphate pathway in malignant tumors. Oncol Lett. (2019) 17:4213-21. doi: 10.3892/ol.2019.10112

76. Liu X, Olszewski K, Zhang Y, Lim EW, Shi J, Zhang X, et al. Cystine transporter regulation of pentose phosphate pathway dependency and disulfide stress exposes a targetable metabolic vulnerability in cancer. Nat Cell Biol. (2020) 22:476-86. doi: 10.1038/s41556-020-0496-x

77. Weber GF. Metabolism in cancer metastasis. Int J Cancer. (2016) 138:20616. doi: 10.1002/ijc.29839

78. Yi W, Clark PM, Mason DE, Keenan MC, Hill C, Goddard WA, et al. Phosphofructokinase 1 glycosylation regulates cell growth and metabolism. Science. (2012) 337:975-80. doi: 10.1126/science.1222278

79. Wang H, Nicolay BN, Chick JM, Gao X, Geng Y, Ren H, et al. The metabolic function of cyclin D3-CDK6 kinase in cancer cell survival. Nature. (2017) 546:426-30. doi: 10.1038/nature22797

80. Hong $\mathrm{X}$, Song $\mathrm{R}$, Song $\mathrm{H}$, Zheng $\mathrm{T}$, Wang $\mathrm{J}$, Liang $\mathrm{Y}$, et al. PTEN antagonises Tcll/hnRNPK-mediated G6PD pre-mRNA splicing which contributes to hepatocarcinogenesis. Gut. (2014) 63:1635-47. doi: 10.1136/gutjnl-2013-305302

81. Yin X, Tang B, Li JH, Wang Y, Zhang L, Xie XY, et al. ID1 promotes hepatocellular carcinoma proliferation and confers chemoresistance to oxaliplatin by activating pentose phosphate pathway. J Exp Clin Cancer Res. (2017) 36:166. doi: 10.1186/s13046-017-0637-7

82. Gao Y, Yang Y, Yuan F, Huang J, Xu W, Mao B, et al. TNFalpha$\mathrm{YAP} / \mathrm{p} 65-\mathrm{HK} 2$ axis mediates breast cancer cell migration. Oncogenesis. (2017) 6:e383. doi: 10.1038/oncsis.2017.83

83. Riganti C, Gazzano E, Polimeni M, Aldieri E, Ghigo D. The pentose phosphate pathway: an antioxidant defense and a crossroad in tumor cell fate. Free Radic Biol Med. (2012) 53:421-36. doi: 10.1016/j.freeradbiomed.2012.05.006

84. Kowalik MA, Guzzo G, Morandi A, Perra A, Menegon S, Masgras I, et al. Metabolic reprogramming identifies the most aggressive lesions at early phases of hepatic carcinogenesis. Oncotarget. (2016) 7:3237593. doi: 10.18632/oncotarget.8632

85. Tebay LE, Robertson H, Durant ST, Vitale SR, Penning TM, DinkovaKostova AT, et al. Mechanisms of activation of the transcription factor Nrf2 by redox stressors, nutrient cues, and energy status and the pathways through which it attenuates degenerative disease. Free Radic Biol Med. (2015) 88(Pt B):108-46. doi: 10.1016/j.freeradbiomed.2015.06.021

86. Hellmich MR, Szabo C. Hydrogen sulfide and cancer. Handb Exp Pharmacol. (2015) 230:233-41. doi: 10.1007/978-3-319-18144-8_12

87. Szabo C, Hellmich MR. Endogenously produced hydrogen sulfide supports tumor cell growth and proliferation. Cell Cycle. (2013) 12:2915-6. doi: 10.4161/cc.26064

88. Zhao H, Li Q, Wang J, Su X, Ng KM, Qiu T, et al. Frequent epigenetic silencing of the folate-metabolising gene cystathioninebeta-synthase in gastrointestinal cancer. PLoS ONE. (2012) 7:e49683. doi: 10.1371/journal.pone.0049683

89. Zhang L, Qi Q, Yang J, Sun D, Li C, Xue Y, et al. An anticancer role of hydrogen sulfide in human gastric cancer cells. Oxid Med Cell Longev. (2015) 2015:636410. doi: 10.1155/2015/636410

90. Wu D, Li J, Zhang Q, Tian W, Zhong P, Liu Z, et al. Exogenous hydrogen sulfide regulates the growth of human thyroid carcinoma cells. Oxid Med Cell Longev. (2019) 2019:6927298. doi: 10.1155/2019/6927298

91. Wang L, Shi H, Liu Y, Zhang W, Duan X, Li M, et al. Cystathionine- $\gamma$-lyase promotes the metastasis of breast cancer via the VEGF signaling pathway. Int J Oncol. (2019) 55:473-87. doi: 10.3892/ijo.2019.4823 
92. Masi Ad, Ascenzi P. $\mathrm{H}_{2} \mathrm{~S}$ : a "Double face" molecule in health and disease. BioFactors. (2013) 39:186-96. doi: 10.1002/biof.1061

93. Zuhra K, Tomé CS, Masi L, Giardina G, Paulini G, Malagrinò F, et al. Nacetylcysteine serves as substrate of 3-mercaptopyruvate sulfurtransferase and stimulates sulfide metabolism in colon cancer cells. Cells. (2019) 8:828. doi: $10.3390 /$ cells 8080828

94. Jurkowska H, Placha W, Nagahara N, Wróbel M. The expression and activity of cystathionine- $\gamma$-lyase and 3-mercaptopyruvate sulfurtransferase in human neoplastic cell lines. Amino Acids. (2011) 41:151-8. doi: 10.1007/s00726-010-0606-3

95. Bronowicka-Adamska P, Bentke A, Wrobel M. Hydrogen sulfide generation from l-cysteine in the human glioblastoma-astrocytoma U-87 MG and neuroblastoma SHSY5Y cell lines. Acta Biochimica Polonica. (2017) 64:1716. doi: 10.18388/abp.2016_1394

96. Ostrakhovitch EA, Akakura S, Sanokawa-Akakura R, Goodwin S, Tabibzadeh S. Dedifferentiation of cancer cells following recovery from a potentially lethal damage is mediated by $\mathrm{H}_{2} \mathrm{~S}-\mathrm{Nampt}$. Exp Cell Res. (2015) 330:135-50. doi: 10.1016/j.yexcr.2014.09.027

97. Untereiner AA, Pavlidou A, Druzhyna N, Papapetropoulos A, Hellmich $\mathrm{MR}$, Szabo C. Drug resistance induces the upregulation of $\mathrm{H}_{2} \mathrm{~S}$-producing enzymes in HCT116 colon cancer cells. Biochem Pharmacol. (2018) 149:17485. doi: 10.1016/j.bcp.2017.10.007

98. Oláh G, Módis K, Törö G, Hellmich MR, Szczesny B, Szabo C. Role of endogenous and exogenous nitric oxide, carbon monoxide and hydrogen sulfide in HCT116 colon cancer cell proliferation. Biochem Pharmacol. (2018) 149:186-204. doi: 10.1016/j.bcp.2017.10.011

99. Szczesny B, Marcatti M, Zatarain JR, Druzhyna N, Wiktorowicz JE, Nagy P, et al. Inhibition of hydrogen sulfide biosynthesis sensitizes lung adenocarcinoma to chemotherapeutic drugs by inhibiting mitochondrial DNA repair and suppressing cellular bioenergetics. Sci Rep. (2016) 6:36125. doi: 10.1038/srep36125

100. Lo M, Wang Y-Z, Gout PW. The x cystine/glutamate antiporter: a potential target for therapy of cancer and other diseases. J Cell Physiol. (2008) 215:593602. doi: $10.1002 /$ jcp. 21366

101. Bianchi MG, Bardelli D, Chiu M, Bussolati O. Changes in the expression of the glutamate transporter EAAT3/EAAC1 in health and disease. Cell Mol Life Sci. (2014) 71:2001-15. doi: 10.1007/s00018-013-1484-0

102. Fazzari J, Lin H, Murphy C, Ungard R, Singh G. Inhibitors of glutamate release from breast cancer cells; new targets for cancer-induced bone-pain. Sci Rep. (2015) 5:8380. doi: 10.1038/srep08380

103. Shiozaki A, Iitaka D, Ichikawa D, Nakashima S, Fujiwara H, Okamoto K, et al. $\mathrm{xCT}$, component of cysteine/glutamate transporter, as an independent prognostic factor in human esophageal squamous cell carcinoma. $J$ Gastroenterol. (2014) 49:853-63. doi: 10.1007/s00535-013-0847-5

104. Stepulak A, Rola R, Polberg K, Ikonomidou C. Glutamate and its receptors in cancer. J Neural Transm. (2014) 121:93344. doi: 10.1007/s00702-014-1182-6

105. Koochekpour S, Majumdar S, Azabdaftari G, Attwood K, Scioneaux R, Subramani D, et al. Serum glutamate levels correlate with Gleason score and glutamate blockade decreases proliferation, migration, and invasion and induces apoptosis in prostate cancer cells. Clin Cancer Res. (2012) 18:5888-901. doi: 10.1158/1078-0432.CCR-12-1308

106. Dornier E, Rabas N, Mitchell L, Novo D, Dhayade S, Marco S, et al. Glutaminolysis drives membrane trafficking to promote invasiveness of breast cancer cells. Nat Commun. (2017) 8:2255. doi: 10.1038/s41467-017-02101-2

107. Kang ES, Lee J, Homma T, Kurahashi T, Kobayashi S, Nabeshima A, et al. xCT deficiency aggravates acetaminophen-induced hepatotoxicity under inhibition of the transsulfuration pathway. Free Rad Res. (2017) 51:8090. doi: 10.1080/10715762.2017.1282157

108. Ji X, Qian J, Rahman SMJ, Siska PJ, Zou Y, Harris BK, et al. xCT (SLC7A11)mediated metabolic reprogramming promotes non-small cell lung cancer progression. Oncogene. (2018) 37:5007-19. doi: 10.1038/s41388-018-0307-z

109. Koppula P, Zhang Y, Shi J, Li W, Gan B. The glutamate/cystine antiporter SLC7A11/xCT enhances cancer cell dependency on glucose by exporting glutamate. J Biol Chem. (2017) 292:14240-9. doi: 10.1074/jbc.M117.798405

110. Lim JKM, Delaidelli A, Minaker SW, Zhang H-F, Colovic M, Yang H, et al. Cystine/glutamate antiporter xCT (SLC7A11) facilitates oncogenic RAS transformation by preserving intracellular redox balance. Proc Natl Acad Sci USA. (2019) 116:9433-42. doi: 10.1073/pnas.1821323116

111. Habib E, Linher-Melville K, Lin H-X, Singh G. Expression of xCT and activity of system $\mathrm{xc}(-)$ are regulated by NRF2 in human breast cancer cells in response to oxidative stress. Redox Biol. (2015) 5:3342. doi: 10.1016/j.redox.2015.03.003

112. Mossmann D, Park S, Hall MN. mTOR signalling and cellular metabolism are mutual determinants in cancer. Nat Rev Cancer. (2018) 18:74457. doi: 10.1038/s41568-018-0074-8

113. Gu Y, Albuquerque CP, Braas D, Zhang W, Villa GR, Bi J, et al. mTORC2 regulates amino acid metabolism in cancer by phosphorylation of the cystine-glutamate antiporter xCT. Mol Cell. (2017) 67:12838.e7. doi: 10.1016/j.molcel.2017.05.030

114. Miyamoto K, Watanabe M, Boku S, Sukeno M, Morita M, Kondo H, et al. xCT inhibition increases sensitivity to vorinostat in a ROS-dependent manner. Cancers. (2020) 12:827. doi: 10.3390/cancers 12040827

115. Yu H, Yang C, Jian L, Guo S, Chen R, Li K, et al. Sulfasalazine-induced ferroptosis in breast cancer cells is reduced by the inhibitory effect of estrogen receptor on the transferrin receptor. Oncol Rep. (2019) 42:82638. doi: 10.3892/or.2019.7189

116. Li Y, Yan H, Xu X, Liu H, Wu C, Zhao L. Erastin/sorafenib induces cisplatinresistant non-small cell lung cancer cell ferroptosis through inhibition of the Nrf2/xCT pathway. Oncol Lett. (2020) 19:323-33. doi: 10.3892/ol.2019.11066

117. Fujii J, Homma T, Kobayashi S. Ferroptosis caused by cysteine insufficiency and oxidative insult. Free Radic Res. (2019) 1-12. doi: 10.1080/10715762.2019.1666983

118. Zhang W, Trachootham D, Liu J, Chen G, Pelicano H, Garcia-Prieto C, et al. Stromal control of cystine metabolism promotes cancer cell survival in chronic lymphocytic leukaemia. Nat Cell Biol. (2012) 14:27686. doi: $10.1038 / \mathrm{ncb} 2432$

119. Coothankandaswamy V, Cao S, Xu Y, Prasad PD, Singh PK, Reynolds $\mathrm{CP}$, et al. Amino acid transporter SLC6A14 is a novel and effective drug target for pancreatic cancer. Br J Pharmacol. (2016) 173:3292306. doi: 10.1111/bph.13616

120. Lieu EL, Nguyen T, Rhyne S, Kim J. Amino acids in cancer. Exp Mol Med. (2020) 52:15-30. doi: 10.1038/s12276-020-0375-3

121. Gupta N, Miyauchi S, Martindale RG, Herdman AV, Podolsky R, Miyake $\mathrm{K}$, et al. Upregulation of the amino acid transporter ATB0,+ (SLC6A14) in colorectal cancer and metastasis in humans. Biochim Biophys Acta. (2005) 1741:215-23. doi: 10.1016/j.bbadis.2005.04.002

122. Gupta N, Prasad PD, Ghamande S, Moore-Martin P, Herdman AV, Martindale RG, et al. Up-regulation of the amino acid transporter $\operatorname{ATB}(0,+)$ (SLC6A14) in carcinoma of the cervix. Gynecol Oncol. (2006) 100:813. doi: 10.1016/j.ygyno.2005.08.016

123. Karunakaran S, Umapathy NS, Thangaraju M, Hatanaka T, Itagaki S, Munn DH, et al. Interaction of tryptophan derivatives with SLC6A14 $(\mathrm{ATB} 0,+)$ reveals the potential of the transporter as a drug target for cancer chemotherapy. Biochem J. (2008) 414:343-55. doi: 10.1042/BJ200 80622

124. Pissimissis N, Papageorgiou E, Lembessis P, Armakolas A, Koutsilieris M. The glutamatergic system expression in human PC-3 and LNCaP prostate cancer cells. Anticancer Res. (2009) 29:371-7.

125. Bianchi MG, Franchi-Gazzola R, Reia L, Allegri M, Uggeri J, Chiu M, et al. Valproic acid induces the glutamate transporter excitatory amino acid transporter-3 in human oligodendroglioma cells. Neuroscience. (2012) 227:260-70. doi: 10.1016/j.neuroscience.2012.09.055

126. Aronica E, Gorter JA, Ijlst-Keizers H, Rozemuller AJ, Yankaya B, Leenstra S, et al. Expression and functional role of mGluR3 and mGluR5 in human astrocytes and glioma cells: opposite regulation of glutamate transporter proteins. Eur J Neurosci. (2003) 17:210618. doi: 10.1046/j.1460-9568.2003.02657.x

127. Pedraz-Cuesta E, Christensen S, Jensen AA, Jensen NF, Bunch L, Romer $\mathrm{MU}$, et al. The glutamate transport inhibitor DL-Threo- $\beta$-Benzyloxyaspartic acid (DL-TBOA) differentially affects SN38- and oxaliplatin-induced death of drug-resistant colorectal cancer cells. BMC Cancer. (2015) 15:411. doi: 10.1186/s12885-015-1405-8

128. Altan B, Kaira K, Watanabe A, Kubo N, Bao P, Dolgormaa G, et al. Relationship between LAT1 expression and resistance to chemotherapy in 
pancreatic ductal adenocarcinoma. Cancer Chemother Pharmacol. (2018) 81:141-53. doi: 10.1007/s00280-017-3477-4

129. White MA, Lin C, Rajapakshe K, Dong J, Shi Y, Tsouko E, et al. Glutamine transporters are targets of multiple oncogenic signaling pathways in prostate cancer. Mol Cancer Res. (2017) 15:1017-28. doi: 10.1158/1541-7786.MCR-16-0480

130. Muir A, Danai LV, Gui DY, Waingarten CY, Lewis CA, Vander Heiden MG. Environmental cystine drives glutamine anaplerosis and sensitizes cancer cells to glutaminase inhibition. Elife. (2017) 6:e27713. doi: 10.7554/eLife.27713

131. Lian G, Gnanaprakasam JR, Wang T, Wu R, Chen X, Liu L, et al. Glutathione de novo synthesis but not recycling process coordinates with glutamine catabolism to control redox homeostasis and directs murine T cell differentiation. Elife. (2018) 7:e36158. doi: 10.7554/eLife.36158

132. Scalise M, Pochini L, Console L, Losso MA, Indiveri C. The Human SLC1A5 (ASCT2) amino acid transporter: from function to structure and role in cell biology. Front Cell Dev Biol. (2018) 6:96. doi: 10.3389/fcell.2018. 00096

133. Scalise M, Pochini L, Pingitore P, Hedfalk K, Indiveri C. Cysteine is not a substrate but a specific modulator of human ASCT2 (SLC1A5) transporter. FEBS Lett. (2015) 589:3617-23. doi: 10.1016/j.febslet.2015.10.011

134. Gaglio D, Metallo CM, Gameiro PA, Hiller K, Danna LS, Balestrieri C, et al. Oncogenic K-Ras decouples glucose and glutamine metabolism to support cancer cell growth. Mol Syst Biol. (2011) 7:523. doi: 10.1038/msb. 2011.56

135. Conrad M, Pratt DA. The chemical basis of ferroptosis. Nat Chem Biol. (2019) 15:1137-47. doi: 10.1038/s41589-019-0408-1
136. Zhou B, Liu J, Kang R, Klionsky DJ, Kroemer G, Tang D. Ferroptosis is a type of autophagy-dependent cell death. Semin Cancer Biol. (2019). doi: 10.1016/j.semcancer.2019.03.002. [Epub ahead of print].

137. Liu N, Lin X, Huang C. Activation of the reverse transsulfuration pathway through NRF2/CBS confers erastin-induced ferroptosis resistance. $\mathrm{Br} \mathrm{J}$ Cancer. (2020) 122:279-92. doi: 10.1038/s41416-019-0660-x

138. Zhu J, Berisa M, Schworer S, Qin W, Cross JR, Thompson CB. Transsulfuration activity can support cell growth upon extracellular cysteine limitation. Cell Metab. (2019) 30:865-76.e5. doi: 10.1016/j.cmet.2019.09.009

139. Cramer SL, Saha A, Liu J, Tadi S, Tiziani S, Yan W, et al. Systemic depletion of L-cyst(e)ine with cyst(e)inase increases reactive oxygen species and suppresses tumor growth. Nat Med. (2017) 23:120-7. doi: 10.1038/nm.4232

140. Kshattry S, Saha A, Gries P, Tiziani S, Stone E, Georgiou G, et al. Enzymemediated depletion of l-cyst(e)ine synergizes with thioredoxin reductase inhibition for suppression of pancreatic tumor growth. NPJ Prec Oncol. (2019) 3:16. doi: 10.1038/s41698-019-0088-z

Conflict of Interest: The author declares that the research was conducted in the absence of any commercial or financial relationships that could be construed as a potential conflict of interest.

Copyright (c) 2020 Serpa. This is an open-access article distributed under the terms of the Creative Commons Attribution License (CC BY). The use, distribution or reproduction in other forums is permitted, provided the original author(s) and the copyright owner(s) are credited and that the original publication in this journal is cited, in accordance with accepted academic practice. No use, distribution or reproduction is permitted which does not comply with these terms. 